\title{
氮磷水平和播期对春小麦籽粒灌浆期降落 数值动态变化的影响
}

\author{
赵秀兰 ${ }^{1,2}$ 李文雄 ${ }^{2}$ \\ （1 中国科学院大气物理研究所东亚区域气候-环境重点实验室/全球变化东亚区域中心, 北京 100029） \\ (2 东北农业大学小麦研究室, 哈尔滨 150030)
}

\begin{abstract}
摘 要 利用不同品质类型春小麦 (Triticum aestivum) 品种在大田条件下研究了灌浆期籽粒降落数值动态变化规律 以及氮磷肥与播期的影响效应。结果表明, 开花 $15 \mathrm{~d}$ 至成熟期间, 籽粒降落数值呈先升后降的单峰曲线变化, 并推 知 $\alpha$-淀粉酶活性 (液化值) 呈先降后升的单谷曲线变化。在富钾情况下, 氮素增施, 高蛋白强筋品种降落数值增加, 动态曲线峰值上升且出现时间推迟, 而高蛋白中筋和低蛋白弱筋品种降落数值则降低, 峰值下降且出现时间提前。 磷素增施, 各基因型品种降落数值均降低; 动态曲线峰值、谷值及出现时间因基因型呈不同变化。氮磷( 钾)素平衡 配施是形成较高降落数值 (较低 $\alpha$-淀粉酶活性) 的关键。在无水分胁迫情况下, 光温互作是影响各基因型籽粒降落 数值动态形成的首要条件, 其次为降水; 且在光温因子互作中, 光合有效辐射为最敏感因子。较高的光温条件互作 是形成各品种较高降落数值的基础, 在此基础上增加光合有效辐射则使高蛋白强筋品种降落数值增加; 而以此为 基础, 在一定水平光照条件限度内, 增加光合有效辐射则使高蛋白中筋和低蛋白弱筋品种降落数值增加, 超过限度 则使其降低。气象条件的影响作用及基因型差异可通过曲线动态变化反映出来。不同基因型降落数值在不同环 境条件(氮磷肥水平和气象条件)下变异不同。
\end{abstract}

关键词 春小麦 籽粒降落数值 动态变化 氮磷水平 播期

\section{EFFECT OF NITROGEN AND PHOSPHORUS LEVEL AND SOWING DATE ON DYNAMIC CHANGE IN GRAIN FALLING NUMBER IN SPRING WHEAT IN GRAIN FILLING}

\author{
ZHAO Xiu-Lan ${ }^{1,2}$ and LI Wen-Xiong ${ }^{2}$ \\ (1 Key Laboratory of Regional Climate-Environment for Temperate East Asia, Institute of Atmospheric Physics, Chinese Academy of \\ Sciences \& START Regional Center for Temperate East Asia, Beijing 100029, China) \\ (2 Northeast Agricultural University, Harbin 150030, China)
}

\begin{abstract}
Wheat grain falling number $(G F N)$ is an important index that indicates the alpha-amylase activity and starch quality properties of wheat. The temporal dynamics of $G F N$ and the effects of environmental conditions on GFN during grain filling have been scarcely reported systematically in the literature. In the present paper, field experiments were carried out in Harbin in 2002 to investigate temporal patterns in $G F N$, and how GFN was affected by $\mathrm{N}$ and $\mathrm{P}$ treatments and meteorological conditions during grain filling. Three genotypes of spring wheat with different qualities were used: a high protein-rich gluten genotype ('Wildcat'), a high protein-medium gluten genotype ('DN7742') and a low protein-poor gluten genotype ( 'NKH9'). The N and P applications included four treatments: $225 \mathrm{~kg} \bullet \mathrm{hm}^{-2} \mathrm{~N}, 450 \mathrm{~kg} \bullet \mathrm{hm}^{-2} \mathrm{P}_{2} \mathrm{O}_{5}(\mathrm{~F} 1) ; 300 \mathrm{~kg} \bullet \mathrm{hm}^{-2} \mathrm{~N}, 300 \mathrm{~kg} \bullet$ $\mathrm{hm}^{-2} \mathrm{P}_{2} \mathrm{O}_{5}$ (F2); $300 \mathrm{~kg} \bullet \mathrm{hm}^{-2} \mathrm{~N}, 450 \mathrm{~kg} \bullet \mathrm{hm}^{-2} \mathrm{P}_{2} \mathrm{O}_{5}$ (F3) and $300 \mathrm{~kg} \bullet \mathrm{hm}^{-2} \mathrm{~N}, 600 \mathrm{~kg} \bullet \mathrm{hm}^{-2} \mathrm{P}_{2} \mathrm{O}_{5}$ (F4). The results showed that temporal changes in GFN after anthesis could be fitted with a third-order convex curve ( single peak curve), indicating that $G F N$ rose in the initial stages and then fell during the middle and upper stages of grain filling. The effects of genotype and environmental factors on GFN formation were compared using this fitted curve. The temporal pattern in alpha-amylase activity fell to a greater extent during the initial stage and then rose weakly in the medium and upper stage. The results also indicated that from the 15th day after anthesis to maturity, with increasing nitrogen levels, medium phosphorus and high potassium levels (450
\end{abstract}


$\left.\mathrm{kg} \bullet \mathrm{hm}^{-2} \mathrm{P}_{2} \mathrm{O}_{5}, 600-630 \mathrm{~kg} \bullet \mathrm{hm}^{-2} \mathrm{~K}_{2} \mathrm{O}\right), G F N$ in the high protein-rich gluten genotype increased and the peak value rose but was delayed, and $G F N$ decreased and the curve peak values fell but was ahead in both the high protein-medium gluten and low protein-poor gluten genotypes. GFN in the three genotypes all decreased with increasing phosphorus levels in the medium or low nitrogen treatments and at high potassium levels ( 300 $\mathrm{kg} \bullet \mathrm{hm}^{-2} \mathrm{~N}, 600-610 \mathrm{~kg} \bullet \mathrm{hm}^{-2} \mathrm{~K}_{2} \mathrm{O}$ ), and the curve differed among the three genotypes. The balance of nitrogen, phosphorus and potassium inputs was the key to forming higher GFN (lower alpha-amylase activity). Under conditions of moderate rainfall, the interaction of temperature and sunlight was the predominant influence on temporal formation patterns of $G F N$ for different genotypes during grain filling, rainfall was the second, and PAR was the most sensitive among all the meteorological elements influencing the dynamic formation of $G F N$. Higher $G F N$ was formed in all genotypes under conditions of high sunlight and high temperatures. Under conditions of high sunlight and temperature, the GFN in the high protein-rich gluten genotype increased with increasing PAR. The effects of meteorological conditions as well as differences among genotypes on GFN could be modelled by curve changes in the third-order equation. The variation of $G F N$ in different genotypes under different environmental conditions (nitrogen and phosphorus fertilization and meteorological conditions) had significant affects on $G F N$.

Key words Spring wheat, Grain falling number, Dynamic Change, Nitrogen and phosphorus level, Sowing date

降落数值是一个表征小麦( Triticum aestivum) 淀 粉品质的重要性状, 已越来越受到关注。它反映了 $\alpha$-淀粉酶使淀粉凝胶液化的能力, 其大小可指示 $\alpha$ 淀粉酶活性的高低且两者呈极显著负相关 (Kettlewell \& Cashman, 1997; Grausgruber et al ., 2000; 徐兆 飞等, 2000; Alaru et al , 2003)。所以, 可把降落数值 作为表征 $\alpha$-淀粉酶活性的间接指标。籽粒发育期是 小麦产量和品质形成的关键时期。该时期籽粒 $\alpha$-淀 粉酶含量与活性的动态变化直接影响着籽粒发育过 程中淀粉水解状况的动态变化, 对籽粒淀粉品质形 成和穗发芽发生具有重要作用。小麦降落数值 ( $\alpha-$ 淀粉酶活性)除受基因型决定外,环境条件对其影响 显著。施氮可提高 $\alpha$-淀粉酶活性, 增加穗发芽率。 生长期降水适度增多, 成熟时能得到适宜降落数值, 但降水过多易使其降低且穗发芽率增加; 干旱条件 则对应相反的结果。从冷凉区转移到温暖区种植, $30 \%$ 品种籽粒成熟前 $\alpha$-淀粉酶活性显著增高 (秦代 红, 1989, 1990; Kettlewell \& Cashman, 1997; Grausgruber et al ., 2000; Lunn et al ., 2001; Alaru et al , 2003; 范 雪梅等, 2004)。前人关于降落数值动态及环境影响 的研究, 尚处于对成熟或成熟前籽粒的初步探讨。 本文则以不同品质类型春小麦品种为材料,在施肥 和播期试验基础上, 对灌浆期籽粒降落数值的变化 进行测定和曲线拟合, 试图揭示灌浆期籽粒降落数 值动态变化规律以及氮磷肥与气象条件的影响效 应, 旨在为进一步丰富小麦淀粉品质形成理论和探 索穗发芽机理,合理利用气候条件和调整栽培措施, 减少穗发芽危害和获得较好的淀粉品质提供理论依
据。

\section{1 材料和方法}

\section{1 材料}

3 个不同品质类型春小麦品种。高蛋白强筋低 产品种: ‘野猫” ( 'Wildcat'), 粗蛋白含量 $15 \%$ $19 \%$, 湿面筋含量 $40 \% \sim 60 \%$, 干面筋含量 $11.0 \%$ $\sim 14.0 \%$, 干面筋指数 $65 \% \sim 95 \%$, 面包体积 $825 \sim$ $925 \mathrm{ml}$, 产量水平 $3800 \sim 5200 \mathrm{~kg} \cdot \mathrm{hm}^{-2}$; 高蛋白中强 筋高产品种: ‘东农 7742’( ‘DN7742’), 粗蛋白含量 15\% 18\%, 湿面筋含量 $40 \% \sim 55 \%$, 干面筋含量 $10.0 \% \sim 13.5 \%$, 干面筋指数 $35 \% \sim 55 \%$, 面包体积 $600 \sim 820 \mathrm{ml}$, 产量水平 $4500 \sim 6300 \mathrm{~kg} \bullet \mathrm{hm}^{-2}$; 低蛋 白弱筋高产品种: ‘新克旱 9' ('NKH9'), 粗蛋白含 量 $11 \% \sim 14 \%$, 湿面筋含量 $30 \% \sim 40 \%$, 干面筋含 量 $7.5 \% \sim 11.0 \%$, 干面筋指数 $25 \% \sim 40 \%$, 面包体 积 $500 \sim 660 \mathrm{ml}$, 产量水平 $4500 \sim 6000 \mathrm{~kg} \bullet \mathrm{hm}^{-2}$ 。

\section{2 方法}

\section{2 .1 施肥与播期试验}

试验于 2002 年在东北农业大学校内试验田进 行。施肥试验地基础肥力为有机质 $3.4 \%$, 全氮 $0.13 \%$, 全磷 $0.097 \%$, 全钾 $1.12 \%$, 速效氮 $92.7 \mathrm{mg}$ • $\mathrm{kg}^{-1}$, 速效磷 $68.0 \mathrm{mg} \bullet \mathrm{kg}^{-1}$, 速效钾 $197.7 \mathrm{mg} \bullet \mathrm{kg}^{-1}$ 。 各小区均采用测土施肥, 不同处理氮磷钾水平与比 例设计如下, F1: 纯 $\mathrm{N} 225 \mathrm{~kg} \cdot \mathrm{hm}^{-2}, \mathrm{P}_{2} \mathrm{O}_{5} 450 \mathrm{~kg}$ ・ $\mathrm{hm}^{-2}, \mathrm{~K}_{2} \mathrm{O} 630 \mathrm{~kg} \bullet \mathrm{hm}^{-2}$; F2: 纯 N $300 \mathrm{~kg} \bullet \mathrm{hm}^{-2}, \mathrm{P}_{2} \mathrm{O}_{5}$ $300 \mathrm{~kg} \bullet \mathrm{hm}^{-2}, \mathrm{~K}_{2} \mathrm{O} 600 \mathrm{~kg} \bullet \mathrm{hm}^{-2}$; F3: 纯 N $300 \mathrm{~kg} \bullet$ 
$\mathrm{hm}^{-2}, \mathrm{P}_{2} \mathrm{O}_{5} 450 \mathrm{~kg} \bullet \mathrm{hm}^{-2}, \mathrm{~K}_{2} \mathrm{O} 600 \mathrm{~kg} \bullet \mathrm{hm}^{-2} ; \mathrm{F} 4$ : 纯 $\mathrm{N}$ $300 \mathrm{~kg} \bullet \mathrm{hm}^{-2}, \mathrm{P}_{2} \mathrm{O}_{5} 600 \mathrm{~kg} \bullet \mathrm{hm}^{-2}, \mathrm{~K}_{2} \mathrm{O} 610 \mathrm{~kg} \bullet \mathrm{hm}^{-2}$ 。 小区面积 $14.0 \mathrm{~m}^{2}$, 重复 4 次, 随机区组排列, 等行距 人工条播 $(19 \mathrm{~cm})$ 。

试验地富钾, 基础肥力速效钾含量 (含 $\mathrm{K}_{2} \mathrm{O} 580$ $\mathrm{kg} \cdot \mathrm{hm}^{-2}$ )测定接近 1 级, 且空间分布相对均匀。各 处理所施磷钾肥中 $\mathrm{K}_{2} \mathrm{O}$ 的量 $\left(15 \sim 58 \mathrm{~kg} \cdot \mathrm{hm}^{-2}\right)$ 相对 于基础肥力中速效钾 $\left(\mathrm{K}_{2} \mathrm{O}\right)$ 的量增加很小 ( $2 \%$ $9 \%$ ), 且处理间 $\mathrm{K}_{2} \mathrm{O}$ 含量的变幅在 $6 \%$ 以内, 而处理 间纯 $\mathrm{N}$ 和 $\mathrm{P}_{2} \mathrm{O}_{5}$ 含量的变幅最高分别达到 $28 \%$ 和 $68 \%$, 所以施肥试验中 $\mathrm{K}_{2} \mathrm{O}$ 的少量增加对降落数值 的影响可以忽略不计。

分期播种试验的 3 个播期分别为 4 月 12 日、 4 月 20 日和 4 月 28 日, 施肥水平为纯 $\mathrm{N} 188 \mathrm{~kg}$ ・ $\mathrm{hm}^{-2}, \mathrm{P}_{2} \mathrm{O}_{5} 300 \mathrm{~kg} \cdot \mathrm{hm}^{-2}$; 每个播期设 2 次重复, 小区 面积 $14.0 \mathrm{~m}^{2}$ 。各试验氮肥与磷肥均分别选用尿素 和磷酸二氢钾, 且以种肥形式深施; 密度均为 600 万 株・ $\mathrm{hm}^{-2}$ 。

\subsection{2 样品制备}

从播种始进行发育期观测直至成熟。对抽穗和 开花均在同一天的茎进行标记, 自开花始, 每隔 $5 \mathrm{~d}$ 取样 1 次, 直至成熟。开花 $5 \mathrm{~d}$ 时, 依品种不同取样 $100 \sim 200$ 穗, 随灌浆进行, 取样数量动态递减。样品 经过 $105{ }^{\circ} \mathrm{C}$ 杀青 $15 \mathrm{~min}$ (赵世杰等, 1998), 而且依据 成熟程度的增加, 杀青时间渐减, 直至成熟时完全不 杀青; 经风干脱粒后, 用 3100 小型磨粉碎获全麦粉 备用。

\subsection{3 测定方法}

采用 ICC 方法和瑞典 Perten 公司降落数值仪测 定。测定过程: 将蒸馏水注入水浴锅中, 达到标线后 开机加热至 $100{ }^{\circ} \mathrm{C}$, 打开冷凝水。将装有 $7 \mathrm{~g}$ 样品的 粘度管倾斜 $45^{\circ}$ 角, 加入 $25 \mathrm{ml}$ 水 $\left(20{ }^{\circ} \mathrm{C}\right)$, 塞好皮塞, 使试管保持直立,上下摇动 10 次, 使面粉充分悬浮。 然后去塞, 插入搅拌器, 立即将试管置于水浴锅中, 复原自动搅拌器装置, 计时器自动计时开始。5 $\mathrm{s}$ 后 搅拌器装置擒纵器自动抓起搅拌器, 并按每秒钟两 个来回的频率进行搅拌。60 $\mathrm{s}$ 后自动释放摚拌器, 搅拌器在重力作用下在悬浮液凝胶中沉降, 降至底 部时, 计时器计时自动停止, 结束试验。自动打印出 的计时器记录的时间 (秒数), 即为降落数值 $F_{0}(\mathrm{~s})$, 求其相当于 $14 \%$ 湿基时样品的降落数值 $F(\mathrm{~s}): F=$ $F_{0} \times \frac{100-14}{100-M}$, 式中 $M$ 为百克样品水分含量 $(\mathrm{g})$ 。液
化值 $L$ 可用下式求得: $L=\frac{6000}{F-50}$ 。

\subsection{4 气象资料}

2002 年哈尔滨市 4 7 月逐日气象资料来自黑 龙江省气象台。 $\geqslant 10{ }^{\circ} \mathrm{C}$ 积温、光合有效辐射、降水 及气温日较差逐候累计值分别为 $\sum_{t=t_{0}}^{t_{i}}\left(\bar{T}_{t}-10\right)$, $\sum_{t=t_{0}}^{t_{i}} Q_{t}, \sum_{t=t_{0}}^{t_{i}} R_{t}, \sum_{t=t_{0}}^{t_{i}} \Delta T_{t}$ 。式中: $t_{0}$ 为开花日, $t_{i}$ 为开花 后取样日; $\bar{T} 、 Q 、 R 、 \Delta T$ 分别为日平均气温 $\left({ }^{\circ} \mathrm{C}\right) 、 日$ 光合有效辐射总量 $\left(\mathrm{MJ} \cdot \mathrm{m}^{-2} \cdot \mathrm{d}^{-1}\right)$ 、日降水总量 $(\mathrm{mm})$ 和气温日较差 $\left({ }^{\circ} \mathrm{C}\right)$ 。

\subsection{5 数据处理与分析方法}

采用 NOSA 统计软件系统进行曲线方程的拟 合。将灌浆期籽粒降落数值田间实测资料 (图 1 与 图 2) 按品种分别进行肥力与播期总平均 (图 3), 再 加上原始实测资料总计 24 个序列。以这些序列为 因变量, 实测资料的观测时间为自变量, 利用最小二 乘法进行曲线拟合。

\section{2 结果与分析}

\section{1 降落数值动态变化规律}

对拟合结果的分析可知, 开花后 $15 \mathrm{~d}$ 至成熟期 间, 小麦籽粒降落数值随时间动态变化规律均符合 一元三次多项式曲线, 其拟合精度在所有尝试拟合 的曲线方程类型中最高, 回归效果最好, 多数回归方 程 $F$ 值能通过 0.05 的信度检验。一元三次多项式 曲线方程可表达为: $f(t)=a t^{3}+b t^{2}+c t+d$, 式中, $f(t)$ 为降落数值, $t=T / 5$ ( $T$ 为小麦开花后的天数), $a 、 b 、 c 、 d$ 为方程中各项系数。各变量和参数的生 物学意义如下: 降落数值动态变化速度为 $V=f^{\prime}(t)$ $=3 a t^{2}+2 b t+c$, 加速度为 $A=f^{\prime \prime}(t)=6 a t+2 b$, 曲 线极值 (峰值与谷值) $t_{1}=\left(-b-\left(b^{2}-3 a c\right)^{1 / 2}\right) / 3 a$ 与 $t_{2}=\left(-b-\left(b^{2}+3 a c\right)^{1 / 2}\right) / 3 a$; 当 $A=0$, 即 $t_{0}=-$ $b / 3 a$ 时为曲线拐点, 此点对应籽粒降落数值的最大 (极限) 速度。在 $t$ 的取值范围内, 绝大多数 $f^{\prime \prime}(t)<$ 0 , 曲线基本为凸性。因此, 春小麦灌浆期籽粒降落 数值随时间动态变化的普遍规律呈先增加后降低的 单峰曲线变化(图 3), 基因型与环境要素(氮磷肥与 气象条件)的影响可通过方程特征量体现出来(表 1)。

\section{2 氮磷的调节作用}

由图 1 和表 1 可知, 随氮素增施 (由 F1 增加到 F3 时), 高蛋白强筋品种降落数值增加, 峰值上升且 
表 1 籽粒降落数值积累曲线方程的极值和拐点

Table 1 Parameters of accumulation equation of grain falling number ( GFN)

\begin{tabular}{|c|c|c|c|c|c|c|c|c|c|}
\hline \multirow{2}{*}{$\begin{array}{c}\text { 处理 } \\
\text { Treatment }\end{array}$} & \multirow{2}{*}{$\begin{array}{l}\text { 基因型 } \\
\text { Genotype }\end{array}$} & \multicolumn{8}{|c|}{ 有关的曲线极值和拐点参数 Curve parameters } \\
\hline & & $T_{\mathrm{s}}$ & $T_{\mathrm{m}}$ & $Y_{\mathrm{s}}$ & $Y_{\mathrm{m}}$ & $T_{\mathrm{c}}$ & $A_{\mathrm{L}}$ & $A_{\mathrm{R}}$ & $V_{\mathrm{m}}$ \\
\hline 总平均 Average-all & “野猫’ ‘Wildcat’ & & 29.3 & & 423 & & & & \\
\hline & “东农 7742’ ‘DN7742' & 35.0 & 23.1 & 303 & 391 & 29.1 & - & + & -55.5 \\
\hline & ‘新克旱 9’ ‘NKH9’ & 31.6 & 24.8 & 357 & 372 & 28.2 & - & + & -16.2 \\
\hline F1 & ‘野猫’’Wildcat’ & & 29.6 & & 395 & & & & \\
\hline $\mathrm{F} 2$ & “野猫' ‘Wildcat' & & 29.5 & & 427 & 21.4 & + & - & 135.8 \\
\hline F3 & “野猫' ‘Wildcat' & & 29.8 & & 419 & 19.5 & + & - & 143.3 \\
\hline $\mathrm{F} 4$ & ‘野猫’'Wildcat’ & & 30.1 & & 419 & 23.0 & + & - & 149.8 \\
\hline $\mathrm{F} 1$ & “东农 7742’ ‘DN7742’ & & 26.4 & & 440 & & & & \\
\hline $\mathrm{F} 2$ & “东农 7742’ ‘DN7742’ & 31.3 & 22.1 & 325 & 415 & 26.7 & - & + & -73.2 \\
\hline F3 & “东农 7742’ ‘DN7742’ & 31.2 & 21.7 & 285 & 394 & 26.4 & - & + & -85.7 \\
\hline $\mathrm{F} 4$ & “东农 7742’ ‘DN7742’ & 31.2 & 21.5 & 295 & 409 & 26.3 & - & + & -88.1 \\
\hline F1 & ‘新克旱 9’ ‘NKH9’ & & 28.2 & & 385 & & & & \\
\hline $\mathrm{F} 2$ & ‘新克旱 9’ ‘ NKH9' & 31.5 & 24.2 & 380 & 402 & 27.9 & - & + & -22.9 \\
\hline F3 & ‘新克旱 9’ ‘ NKH9’ & 29.7 & 26.7 & 345 & 346 & 28.2 & - & + & -2.1 \\
\hline $\mathrm{F} 4$ & ‘新克旱 9’ ‘ NKH9' & 31.8 & 25.2 & 342 & 356 & 28.5 & - & + & -16.0 \\
\hline 播期 1 Sowing date 1 & ‘野猫’’Wildcat’ & & 30.0 & & 417 & 18.5 & + & - & 164.1 \\
\hline 播期 2 Sowing date 2 & ‘野猫' ‘Wildcat' & & 28.1 & & 430 & & & & \\
\hline 播期 3 Sowing date 3 & ‘野猫’‘Wildcat’ & & 22.8 & & 510 & 27.3 & - & + & -87.8 \\
\hline 播期 1 Sowing date 1 & “东农 7742’ ‘DN7742’ & & 20.4 & & 399 & & & & \\
\hline 播期 2 Sowing date 2 & “东农 7742’ ‘DN7742’ & & 24.9 & & 386 & & & & \\
\hline 播期 3 Sowing date 3 & “东农 7742’ ‘DN7742’ & & 29.6 & & 387 & & & & \\
\hline 播期 1 Sowing date 1 & ‘新克旱 9’ ‘NKH9’ & 30.8 & 22.9 & 329 & 356 & 26.9 & - & + & -26.3 \\
\hline 播期 2 Sowing date 2 & ‘新克旱 9’ ‘ NKH9’ & 28.6 & 21.7 & 357 & 380 & 25.1 & - & + & -24.9 \\
\hline 播期 3 Sowing date 3 & ‘新克旱 9’ ‘ NKH9' & & 25.3 & & 419 & & & & \\
\hline
\end{tabular}

$T_{\mathrm{s}}$ : 谷值出现的时间 Time corresponding to the vale value (d) $T_{\mathrm{m}}$ : 峰值出现的时间 Time corresponding to the peak value (d) $Y_{\mathrm{s}}$ : 谷值 Vale value $(\mathrm{s}) \quad Y_{\mathrm{m}}$ : 峰值 Peak value $(\mathrm{s}) \quad T_{\mathrm{c}}$ : 曲线拐点处对应的时间 Time corresponding to the curve inflexion $(\mathrm{d}) A_{\mathrm{L}}$ : 曲线拐点前降落数值动态变化加 速度 $\left(A_{\mathrm{L}}>0\right.$ 或 $\left.A_{\mathrm{L}}<0\right)$ Dynamic change acceleration of $G F N$ before the curve inflexion $\left(A_{\mathrm{L}}>0\right.$ or $\left.A_{\mathrm{L}}<0\right) \quad A_{\mathrm{R}}$ : 曲线拐点后降落数值动态变化加速度 ( $A_{\mathrm{R}}>0$ 或 $\left.A_{\mathrm{R}}<0\right)$ Dynamic change acceleration of $G F N$ after the curve inflexion $\left(A_{\mathrm{R}}>0\right.$ or $\left.A_{\mathrm{R}}<0\right) \quad V_{\mathrm{m}}$ : 最大变化速度 The biggest dynamic change velocity of $G F N\left(\mathrm{~s}^{\bullet} \mathrm{d}^{-1}\right)$
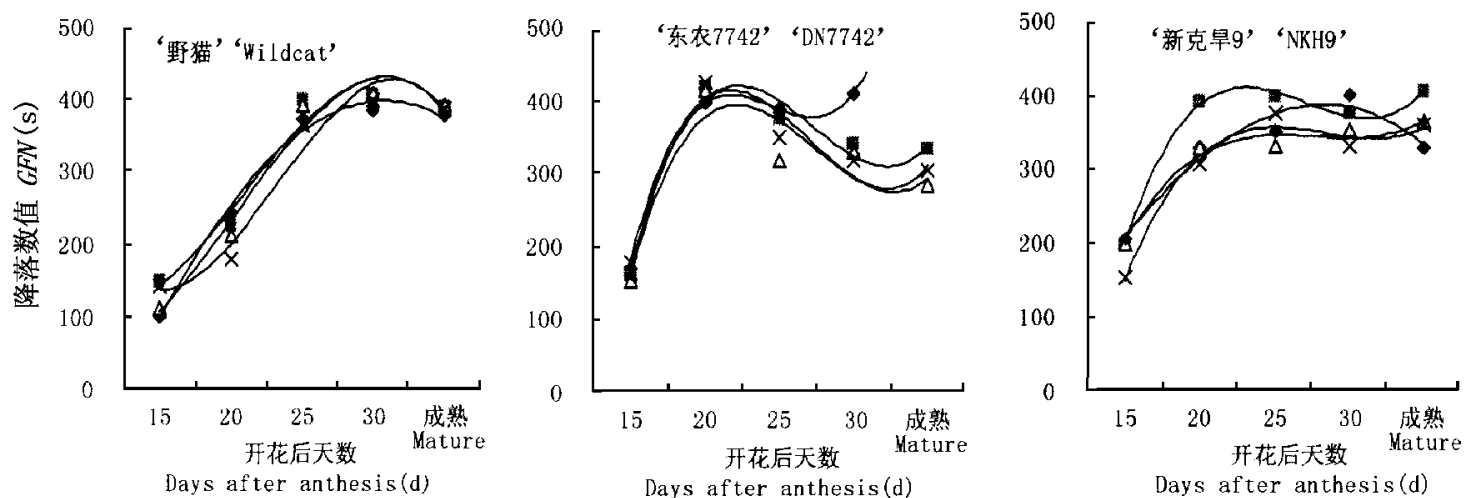

$\mathrm{F} 1 \square \mathrm{F} 2 \triangle \mathrm{F} 3 \times \mathrm{F} 4$

图 1 氮水平与氮磷比例对降落数值动态变化过程的调节

Fig. 1 Regulation of dynamic changes in grain falling number ( GFN) in different $\mathrm{N}$ and $\mathrm{P}$ treatments

出现时间推迟, 而高蛋白中筋和低蛋白弱筋品种降 落数值降低, 峰值下降且出现时间提前; 最大积累速 度及出现时间也发生相应变化。例如, 在开花 $10 \mathrm{~d}$ 至成熟期间, ‘野猫’ 降落数值平均增加 $6.6 \mathrm{~s}$, 峰值
上升 $24 \mathrm{~s}$, 出现时间推迟 $0.2 \mathrm{~d}$; “东农 7742 ’ 降落数 值平均减少 $33.5 \mathrm{~s}$, 峰值下降 $36 \mathrm{~s}$, 出现时间提前 4.7 $\mathrm{d}$ 。随磷素增施, 各基因型品种降落数值均降低, 并 随磷比例增加, 高蛋白强筋和低蛋白弱筋品种降低 
幅度增大而高蛋白中筋品种则减小。例如, 由 F2 增 至 F3 和 F4, “野猫”、“东农 7742’ 和 “新克旱 9’ 降落 数值依次平均降低 10.8 和 20.0 s、26.8 和 11.8 、 38.6 和 $48.4 \mathrm{~s}$ 。磷用量对籽粒降落数值动态形成过 程的影响, 可以通过其动态曲线特征量变化而体现。 高蛋白强筋和低蛋白弱筋品种峰值均下降, 而高蛋 白中筋品种则先下降后上升; 峰值出现时间、谷值及 其出现时间因基因型呈不同变化。例如: 由 F2 增至 $\mathrm{F} 3$ 和 $\mathrm{F} 4$, “新克旱 9’ 峰值依次降低 56、46 s, 出现时 间分别推迟 2.5.1.0 d; 谷值依次降低 $35.38 \mathrm{~s}$, 出现 时间依次提早 $1.8 \mathrm{~d}$ 和推迟 $0.3 \mathrm{~d}$; 最大速度依次降 低 $20.8 、 6.9 \mathrm{~s} \cdot \mathrm{d}^{-1}$, 且出现时间依次推迟 $0.3 、 0.6 \mathrm{~d}$ 。 各品种籽粒降落数值动态变化过程受氮磷肥影响程 度, 低蛋白弱筋和高蛋白中筋品种大于高蛋白强筋 品种。

\section{3 播期的影响}

本试验年份为正常气候年景, 光温条件较好, 降 水充沛, 整个生长期不存在旱涝灾害对小麦生长发 育的影响。将各品种灌浆期降落数值动态变化的实
测资料(图 2), 与对应时间的各气象要素自开花始 逐候累计值进行相关分析, 结果表明, 其与 $\geqslant 10{ }^{\circ} \mathrm{C}$ 积温、光合有效辐射和气温日较差均呈高度显著正 相关 $\left(r=0.6623^{* * *}, 0.6907^{* * *}, 0.6798^{* * *}, n=\right.$ 38 )。为进一步明确各气象要素的影响程度及基因 型差异, 对灌浆期气象要素逐候累计值进行主成分 分析（表 2)。结果表明, 各基因型光温互作性均很 强, 说明光温互作是影响降落数值动态形成的首要 条件,其次为降水。播期间 (以播期 1 为对照) 逐候 气象要素累计值差值与降落数值差值的相关分析表 明, 两者呈显著正相关 $\left(r=0.3925^{*}, n=24\right)$, 说明 光合有效辐射是影响各品种降落数值动态变化的光 温因子中最为敏感的因素。

针对不同播期间降落数值的变化 (图 2)与对应 各气象要素逐候累计值变化的关系, 分析可知: 在没 有水分胁迫情况下, 较高的光温条件互作是 “野猫”、 “东农 7742 ’ 和 “新克旱 9 ’ 品种较高降落数值形成的 基础。在此前提下增加光合有效辐射则增加野猫降 落数值; 而以此为前提, 在一定水平的光照限度内,

表 2 各基因型品种自开花至成熟期间各气象要素开花后逐候累计值主成份分析

Table 2 Principal components analysis of cumulative meteorological elements started from anthesis in a 5-day interval in genotypes during grain-filling

\begin{tabular}{|c|c|c|c|c|}
\hline \multirow{2}{*}{$\begin{array}{c}\text { 累计要素 } \\
\text { Accumulated elements }\end{array}$} & \multicolumn{4}{|c|}{ 基因型 Genotypes } \\
\hline & 综合 All & “野猫’ 'Wildcat' & ‘东农 7742’ ‘DN7742’ & “新克旱 9’ ‘NKH9’ \\
\hline 光合有效辐射 $\left(\mathrm{MJ} \cdot \mathrm{m}^{-2} \cdot \mathrm{d}^{-1}\right) P A R$ & $0.9856^{*}$ & $0.9797^{*}$ & $0.9918^{*}$ & $0.9933^{*}$ \\
\hline 气温日较差 Diurnal temperature range $\left({ }^{\circ} \mathrm{C}\right)$ & $0.9943^{*}$ & $0.9934^{*}$ & $0.9914^{*}$ & $0.9924^{*}$ \\
\hline$\geqslant 10^{\circ} \mathrm{C}$ 积温 $\geqslant 10^{\circ} \mathrm{C}$ Accumulated temperature $\left({ }^{\circ} \mathrm{C}\right)$ & $0.9598^{*}$ & $0.9715^{*}$ & $0.9754^{*}$ & $0.9804^{*}$ \\
\hline 降水 Precipitation（mm） & 0.6289 & 0.6838 & $0.8837^{*}$ & $0.9111^{*}$ \\
\hline 贡献率 Contribution rate（\%) & 81.92 & 83.95 & 82.47 & 94.06 \\
\hline
\end{tabular}

PAR: Photosynthesis active radiation 仅列出第一主成份载荷值 First principal component loading value only $*:$ 表示 $\geqslant 7.0$ 的高载荷值 Stands for the loading value greater than or equal to 7.0

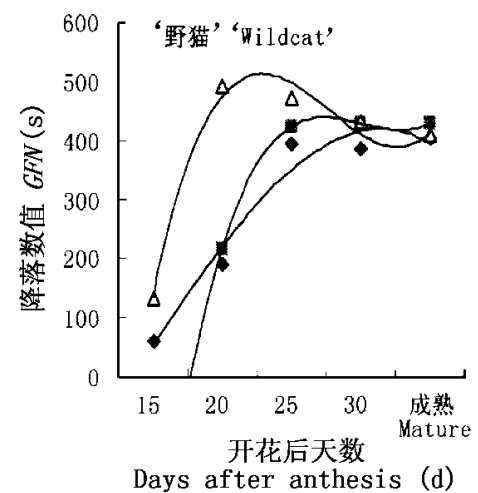

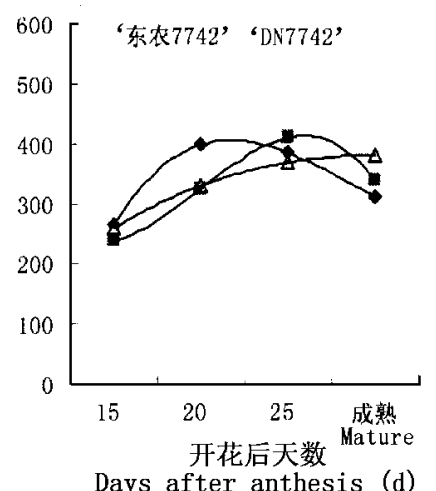

Days after anthesis (d)

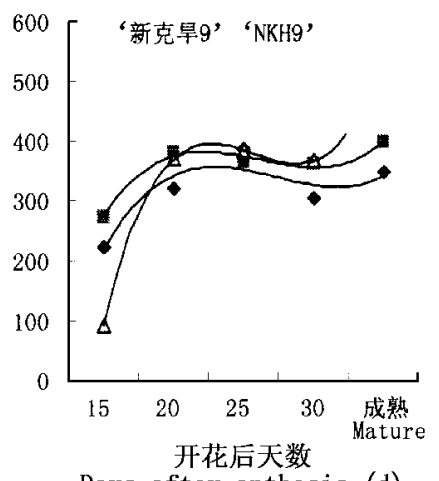

Days after anthesis (d) 


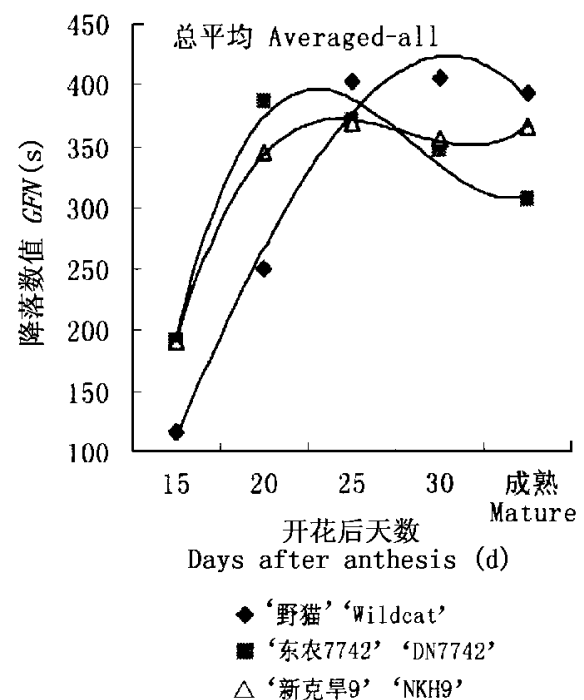

图 3 灌浆期籽粒降落数值动态变化

Fig.3 Dynamic change in grain falling number $(G F N)$ in grain filling

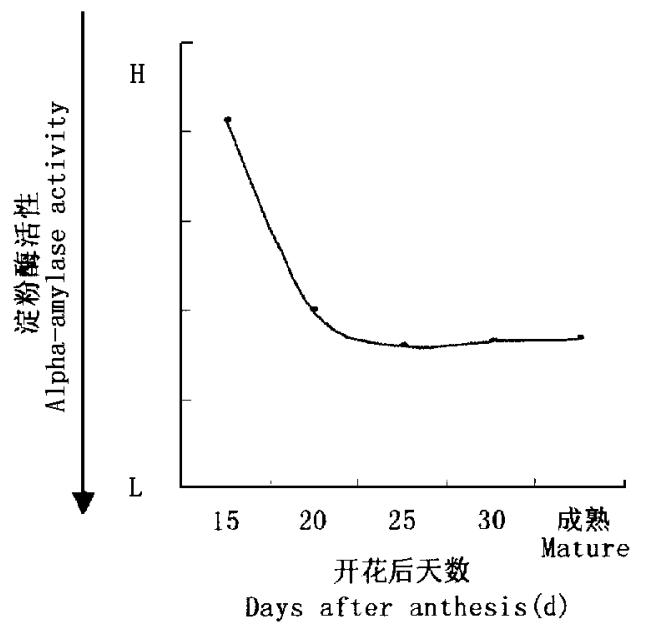

图 4 灌浆期籽粒 $\alpha$-淀粉酶活性动态变化示意图 (3 品种平均)

Fig.4 Sketch map of dynamic change in grain alpha-amylase activity in grain filling (averaged-three genotypes)

继续增加光合有效辐射则增加“东农 7742 ’与 ‘新克 旱 9 的降落数值, 超过限度则其反而降低。进一步 说明光合有效辐射为影响各基因型籽粒降落数值形 成的最敏感因素; ‘野猫’降落数值的形成对高光温 条件耐受性较强, ‘东农 7742’ 和‘新克旱 9’则较弱。 气象条件的影响作用可通过曲线的动态变化反映出 来(图 2 与表 1 )。下面以“野猫’和‘新克旱 9’品种 为例具体说明。以播期 1 自开花始气象要素逐候累 计值的动态变化为对照, ‘野猫’平均每候一定程度 增加光温条件(辐射 $25 \mathrm{MJ} \cdot \mathrm{m}^{-2}$ 、积温 $26{ }^{\circ} \mathrm{C}$ 、气温日 较差 $11{ }^{\circ} \mathrm{C}$ ), 开花后 $15 \mathrm{~d}$ 至成熟期间, 降落数值 (播 期 2) 增加 (平均 $31.8 \mathrm{~s} \cdot 5 \mathrm{~d}^{-1}$ ), 动态曲线峰值增加
$(13 \mathrm{~s})$, 且出现时间提前 $(1.9 \mathrm{~d})$; 当平均每候光温条 件继续增加 (辐射 $31 \mathrm{MJ} \cdot \mathrm{m}^{-2}$ 、积温 $34{ }^{\circ} \mathrm{C}$ 、气温日较 差 $10{ }^{\circ} \mathrm{C}$ ) 时, 降落数值 (播期 3 ) 增加幅度增大 $(76.3$ $\mathrm{s} \cdot 5 \mathrm{~d}^{-1}$ ), 动态曲线峰值上升幅度 (93 s) 及出现时间 的提前幅度 $(7.2$ d) 均增大。对于 ‘ 新克旱 9 ’ 而言, 以播期 3 自开花始气象要素逐候累计值的动态变化 为对照, 平均每候一定程度地增加辐射 (30 MJ • $\left.\mathrm{m}^{-2}\right)$ 、积温 $\left(14{ }^{\circ} \mathrm{C}\right)$ 和气温日较差 $\left(22{ }^{\circ} \mathrm{C}\right)$, 开花后 15 $\mathrm{d}$ 至成熟期间降落数值 (播期 2) 增加 (平均 $42 \mathrm{~s} \cdot$ $5 d^{-1}$ ), 动态曲线峰值下降 (39s) 且出现时间提前 (3.6 d); 当平均每候光合有效辐射增加幅度增大 $\left(40 \mathrm{MJ} \cdot \mathrm{m}^{-2}\right)$, 积温减少 $\left(14{ }^{\circ} \mathrm{C}\right)$, 气温日较差增加 $\left(20{ }^{\circ} \mathrm{C}\right.$ ) 时, 降落数值 (播期 1 ) 反而减小 (平均 37.7 $\left.s \cdot 5 d^{-1}\right)$, 曲线峰值下降幅度 $(63 s$ ) 增大且出现时间 提前幅度 $(2.4 \mathrm{~d})$ 减小。说明 “新克旱 9 ’ 降落数值存 在光照条件的耐受限度。对于两品种而言, 3 个播 期均可以排除高温和水分胁迫的不良影响。上述分 析进一步说明, 光合有效辐射为影响 ‘野猫”和 ‘新克 旱 9 品种降落数值的最敏感因素。

降落数值动态形成过程受气象条件影响的程度 依基因型品种存在差异 (表 1 )。例如, 依 “野猫”、 “新克旱 9’、“东农 7742’ 品种顺序, 曲线峰值的最大 变幅逐渐减小, 依次为 $93 、 63 、 13 \mathrm{~s}$, 而其出现时间依 次变化为 $7.2 、 9.2 、 3.6 \mathrm{~d}$ 。

\section{3 讨 论}

明确灌浆期籽粒降落数值动态变化规律, 而不 局限于利用成熟或成熟前籽粒降落数值来间接探讨 穗发芽和 $\alpha$-淀粉酶活性问题 (Stand, 1983; Xiao et $a l$., 2002; 孙果忠等, 2003; 兰秀锦等, 2004), 对深入 探索小麦淀粉品质形成和穗发芽机理显然更具重要 意义。本试验通过建立曲线拟合方程, 定量揭示出 小麦开花后 $15 \mathrm{~d}$ 至成熟期间籽粒降落数值随时间 动态变化规律符合先增后降的单峰曲线。由 $\alpha$-淀粉 酶活性与降落数值、液化值等指标的关系可知, 降落 数值越小, $\alpha$-淀粉酶活性越强, 反之, $\alpha$-淀粉酶活性 越弱; 液化值是表征 $\alpha$-淀粉酶对糊化物液化作用的 指标, 它与 $\alpha$-淀粉酶活性呈正相关关系 (Kettlewell \& Cashman, 1997; Lunn et al , 2001 王若兰, 2000)。在 已明确籽粒降落数值动态变化规律 (各品种平均)的 前提下, 借助降落数值与液化值的定量关系(徐兆飞 等,2000), 可推知 $\alpha$-淀粉酶的活性可能随时间呈先 降低后上升的单谷曲线变化规律。其曲线型式大致 为: 前期 (开花后 15 至 $20 \mathrm{~d}$ ) 下降幅度很大, 降至最 
低点后小幅回升(图 4)。这里给出的灌浆期籽粒 $\alpha$ 淀粉酶活性动态变化规律, 反应的是在籽粒中直链 和支链淀粉含量不断增长且直支比不断变化 (王芳 和王宪泽, 2004) 的同时, 且籽粒中 $\alpha$-淀粉酶总含量 和单位数量 $\alpha$-淀粉酶活性综合作用条件下, $\alpha$-淀粉 酶对籽粒淀粉的糊化和液化能力 (液化值) 的动态变 化, 而有别于酶生理学中所指单纯的单位数量 $\alpha$-淀 粉酶活性的变化 (Gale, 1983; 秦代红, 1990)。至于籽 粒中 $\alpha$-淀粉酶含量和单位数量 $\alpha$-淀粉酶活性各自的 动态变化规律, 尚待进一步深入研究。本试验结果 是利用体外生物化学方法研究得出, 而小麦籽粒活 体组织中 $\alpha$-淀粉酶数量和活性的动态变化尚待定 论。迄今为止, 尚无明确证据显示小麦活细胞内淀 粉的水解需要 $\alpha$-淀粉酶的参与 (Zeeman et al ., 1998; 王永章和张大鹏, 2002), 因而小麦籽粒活细胞内淀 粉降解的途径也尚待定论。需要说明的是, 本试验 开花后 5 10 d 籽粒降落数值不能测出, 可能与直 链淀粉没有形成或形成的量很少 (王芳和王宪泽, 2004) 有关; $\alpha$-淀粉酶主要水解直链淀粉, 直链淀粉 的量太少则会影响降落数值测定时淀粉糊化和液化 作用的进行。

在富钾的情况下, 氮素增施, 高蛋白强筋品种降 落数值增加, 动态曲线峰值上升且出现时间推迟, 而 高蛋白中筋和低蛋白弱筋品种降落数值则降低, 峰 值下降且出现时间提前。磷素增施, 各基因型品种 降落数值均降低, 动态曲线峰值、谷值及出现时间因 基因型呈不同变化。F2(或 F3)、F1 和 F2 分别为本 试验中高蛋白强筋、高蛋白中筋和低蛋白弱筋品种 形成最高降落数值 (最低 $\alpha$-淀粉酶活性) 的氮磷 (钾) 水平, 进一步说明氮磷 (钾) 肥施用对于籽粒降落数 值的提高依基因型确存在一个界限水平与配比问 题, 并非氮磷( 钾) 肥施用量越高越好, 氮磷( 钾) 素平 衡配施是关键。相比于高蛋白强筋和低蛋白弱筋品 种, 较高的磷钾肥对高蛋白中筋品种形成较低 $\alpha$-淀 粉酶活性有利。高蛋白中筋和低蛋白弱筋品种籽粒 降落数值形成受氮磷 (钾) 影响大于高蛋白强筋品 种。本试验高蛋白中筋和低蛋白弱筋品种随施氮增 加降落数值降低的结论与前人结果 (秦代红, 1989, 1990)相若。

在没有水分胁迫情况下, 光温互作是影响各基 因型籽粒降落数值动态形成的首要条件, 其次为降 水; 而光合有效辐射则为最敏感因子。较高的光温 条件互作是形成各品种较高降落数值的基础。在此 前提下增加光合有效辐射则增加高蛋白强筋品种降
落数值; 以此为前提, 在一定水平的光照限度内, 增 加光合有效辐射则增加高蛋白中筋和低蛋白弱筋品 种降落数值, 超过限度则反而使其降低。气象条件 的影响作用及基因型差异可通过曲线的动态变化反 映出来。高蛋白强筋品种受气象条件影响大于高蛋 白中筋和低蛋白弱筋品种。高蛋白强筋、高蛋白中 筋和低蛋白弱筋品种形成最高降落数值的最佳播期 分别为播期 3、播期 3 和播期 2, 结合各基因型整个 灌浆期光合有效辐射和 $\geqslant 10{ }^{\circ} \mathrm{C}$ 积温的日平均值可 明确: 高蛋白强筋品种降落数值的形成对高光温条 件耐受性较强, 高蛋白中筋和低蛋白弱筋品种则耐 受性较弱, 同时说明高蛋白强筋品种光温潜力很高, 其 $\alpha$-淀粉酶活性不易因高光温条件而升高, 而高蛋 白中筋与低蛋白弱筋品种则光温潜力相对较低。因 此, 在实际生产中, 将基因型与气候条件综合考虑, 选择适宜播期, 在把握灌浆期籽粒降落数值动态变 化普遍规律的前提下, 将 $\alpha$-淀粉酶活性降到相应适 宜值, 以降低穗发芽和成熟籽粒的发芽率, 最终获得 较好的小麦品质。不同基因型降落数值在不同环境 条件(氮磷肥水平和气象条件)下变异不同。就高蛋 白强筋品种而言, 气象条件的影响程度大于氮磷 (钾)肥; 而对于高蛋白中筋和低蛋白弱筋品种, 氮磷 ( 钾)肥的影响大于气象条件。

\section{参 考 文 献}

Alaru M, Laur U, Jama E (2003). Influence of nitrogen and weather conditions on the grain quality of winter triticale. Agronomy Research, 1, 3-10.

Fan XM (范雪梅), Jiang D (姜东), Dai TB (戴廷波), Jing Q (荆奇), Cao WX (曹卫星) (2004). Effect of post-anthesis drought and waterlogging on the quality of grain formation in different wheat varieties. Plant Phytoecologica Sinica (植物生态 学报), 28,680-685. (in Chinese with English abstract)

Gale MD (1983). $\alpha$-amylase activity in wheat. In: Kruger JE, LaBerge DE eds. Third International Symposium on Pre-Harvest Sprouting in Cereals. Westview Press, Boulder, Colorado, USA, $29-35$.

Grausgruber H, Oberforster M, Werteker M (2000). Stability of quality traits in Austrian-grown winter wheats. Field Crops Research, 66, 257-267.

Kettlewell PS, Cashman MM (1997). Alpha-amylase activity of wheat grain from crops differing in grain drying rate. The Journal of Agricultural Science, 128, $127-134$.

Lan XJ (兰秀锦), Zheng YL (郑有良), Liu DC (刘登才), Yan ZH (颜泽洪), Wei YM (魏育明), Zhang ZQ (张志清) (2004). Evaluation on study methods of sprouting tolerance in Wheat. Journal of Sichuan Agricultural University (四川农业大 
学学报), 22, 121 - 125. (in Chinese with English abstract) Lunn GD, Major BJ, Kettlewell PS (2001). Mechanisms leading to excess alpha-amylase activity in wheat (Triticum aestivum L.) grain in the U.K. Journal of Cereal Science, 33, 313-329. Qin DH (秦代红) (1989). The characteristics for preharvest sprouting resistance of wheat. Journal of Sichuan Agricultural University (四川农业大学学报), 7, 188-190. (in Chinese)

Qin DH (秦代红) (1990). The physiology for preharvest sprouting resistance of wheat. Plant Physiology Communication (植物生 理学通讯), 6, 62-64. (in Chinese)

Strand E (1983) . Pre-harvest sprouting in wheat. In: Kruger JE, LaBerge DE eds. Third International Symposium on Pre-Harvest Sprouting in Cereals. Westview Press, Boulder, Colorado, USA, $260-266$.

Sun GZ (孙果忠), Run CS (闰长生), Xiao SH (肖世和) (2003) . The mechanism on wheat pre-harvest sprouting. Review of China Agricultural Science and Technology（中国农业科技导 报), 5, 13-18. (in Chinese with English abstract)

Wang F (王芳), Wang XZ (王宪泽) (2004). Study on the dynamic changes of starch synthesis and their related enzymes in wheat. Journal of Triticeae Crops (麦类作物学报), 24, 57 60. (in Chinese with English abstract)
Wang RL (王若兰) (2000). The study of alpha-amylase activation of sprouting wheat. Journal of Zhengzhou Institute of Technology (郑州工程学院学报), 21, 18-21. (in Chinese with English abstract)

Wang YZ (王永章), Zhang DP (张大鹏) (2002). $\beta$-amylase in developing apple fruits: activities, amounts and subcellular localization. Science in China (Series C) (中国科学 C 辑), 32, $200-210$. (in Chinese with English abstract)

Xiao SH, Zhang XY, Chang YS (2002). Germplasm improvement for pre-harvest sprouting resistance in Chinese white-grained wheat: an overview of the current strategy. Euphytica, 126, 35 -38 .

Xu ZF (徐兆飞), Zhang HY (张惠叶), Zhang DY (张定一) (2000). Wheat Quality and Its Improvement (小麦品质及其改 良). Chinese Meteorological Press, Beijing. (in Chinese)

Zeeman SC, Northorp F, Smith AM (1998). A starch accumulating mutant of Arabidopsis thaliana deficient in a choroplastic starchhydrolyzing enzyme. Plant Journal, 15, 357-365.

Zhao SJ (赵世杰), Liu HS (刘华山), Dong XC (董新纯) (1998). The Guide of Plant Physiological Experiment (植物生 理学实验指导). China Agricultural Science and Technology Press, Beijing. (in Chinese) 